\title{
Acompañemos la vida en el trabajo material: una propuesta de indagación antropológica
}

Joining life in material work: a proposal for anthropological inquiry

\author{
Laura Guzmán Peñuela* \\ Investigadora independiente \\ Luis Alberto Suárez Guava ** \\ Universidad de Caldas, Colombia
}

DOI: $10.22380 / 2539472 X .1992$

\begin{abstract}
$\overline{\text { RESUMEN }}$
Este ensayo propone que la investigación en antropología se realice acompañando la vida en el trabajo material. Planteamos que es necesario dejarse enseñar para trabajar y trabajar para dejarse enseñar. Argumentamos: 1) que debemos cuestionar el usual voluntarismo de los investigadores; 2) que a partir de nuestra participación en el trabajo material podemos transformar las relaciones de campo y nuestras convicciones como investigadores; y 3) que en el trabajo material el mundo es también nuestro maestro. Preferimos la guía de las tareas en realización al condicionamiento de los resultados finales. Creemos que este aprendizaje transformador no solo hará antropologías cercanas a la vida, también abrirá un camino en pos de lograr relaciones menos desiguales en el mundo.
\end{abstract}

Palabras clave: trabajo de campo, trabajo material, antropología, observación participante, desigualdades.

\begin{abstract}
$\overline{\text { ABSTRACT }}$
This article proposes that research in anthropology should be carried out by accompanying life in material work. We propose that it is necessary to allow anthropologists to be taught to work and work to be taught. We argue 1) that we should question the usual voluntarism of researchers; 2) that our participation in material work is potentially transformative of both field relations and our convictions as researchers; and 3) that when we get involved in material work the world is also our teacher. We prefer to be guided by the tasks in progress, rather than by the conditioning that impose predetermined results. We believe that this transformative learning will not only make anthropology closer to life; it will also pave the way for less unequal relationships in the field and in the world.
\end{abstract}

Keywords: fieldwork, material work, anthropology, participant observation, inequalities.

* laura17guzman@gmail.com / https://orcid.org/0000-0002-4034-4903

** luis.suarezg@ucaldas.edu.co / https://orcid.org/0000-0002-0432-8674 


\section{Introducción}

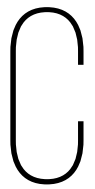

uando en el sur de los Andes colombianos los indígenas pastos dicen que algo o alguien acompaña una actividad es porque su ayuda o presencia la hacen posible ${ }^{1}$. El clima acompaña una cosecha, porque un día sin lluvia es propicio para recoger las papas. Los asistentes a una fiesta ayudan a asar los cuyes, a bailar y a tomar hervidos. Otros ayudan a terminar de acomodar la casa para el evento. En los velorios, algunos de los asistentes cocinan, llevan remesa, cantan o rezan, mientras que otros ocupan una banca en silencio. Todos acompañan: sin ellos no se llevarían a cabo estas reuniones. Las cosas y las personas que acompañan permiten que la vida siga sucediendo.

Este artículo presenta una propuesta para el trabajo de campo en antropología. Consiste en realizar indagaciones que acompañen las vidas mientras están siendo vividas. Como entendemos que uno de los propósitos legítimos de las antropologías recientes - tanto como de las que están por venir- es tratar de evitar la perpetuación de las violencias - las simbólicas, las de género y las de clase-sin dejar de hacer antropología, creemos recomendable eludir las formas de investigación que estudian $a$ la gente o sobre la gente.

Argumentamos que una tarea que puede emprender la antropología es la de acompañar la vida en el trabajo material. Esta propuesta puede aplicarse a investigaciones que quieran aprender de las vidas campesinas, indígenas, artesanas, pescadoras, obreras, recicladoras, cocineras, criadoras de animales, carpinteras, alfareras, tejedoras, joyeras, orfebres, mineras, agricultoras, etc. Las llamamos vidas a ras del suelo por su concrescencia con la tierra, el aire, el agua y todos los materiales del trabajo. El trabajo material nos enseña a reconocer nuestra ignorancia como punto de partida. Creemos que es necesario dejarse enseñar para trabajar y trabajar para dejarse enseñar. Ese aprendizaje transformador no solo hará mejores antropologías, que son necesarias, también ayudará a hacer un mundo amplio para todos.

Proponemos acompañar la vida que está haciéndose. Confiamos en que podemos aprender de ella, en lugar de documentar o elaborar apreciaciones abstractas de una vida que ya no es (ver Ingold 2017). Prestando los brazos y la fuerza al trabajo que la gente y el mundo necesitan conseguimos ocuparnos. Estar vivos consiste en una oscilación constante entre ocupaciones y desocupaciones,

1 Para una aproximación ligeramente distinta a la noción de acompañar de los pastos, ver Saade (2019). 
entre tareas y descansos, entre tomar y soltar el aire, entre alimentarnos y dar comida (Suárez 2021b). Para acompañar esta vida de ocupaciones y desocupaciones podemos asumir las tareas que nos pongan: que su realización sea nuestra labor. Las tareas irán creciendo en nosotros gracias a las repeticiones siempre necesarias del trabajo. La repetición no nos debe persuadir de la impertinencia de las tareas o de la tan mentada inferioridad intelectual de los oficios repetitivos (cfr. Arendt [1958] 2009; ver Anzola [2017] 2020): las tareas que se repiten en el trabajo diario son las que hacen posible la vida.

Esta propuesta hace parte de una búsqueda por luchar contra las relaciones desiguales, no solo durante el trabajo de campo. Creemos, contra una de las convicciones más asentadas de la modernidad, que los modos de hacer son el lugar privilegiado en donde se reproducen los modos de pensar. Lo usual es suponer que la razón solitaria de los pensadores se ilumina de repente y produce, como por arte de magia, nuevas formas de pensamiento. Seguimos a Marx y a Engels cuando afirman que los modos de pensar son un resultado de los modos de producir, que son la forma en que la vida misma se manifiesta (ver Marx y Engels [1845] 1968; Ingold 2011).

A partir de la apuesta de Marx y Engels, Luis Guillermo Vasco (2002) propuso que, para conseguir pensar de un modo distinto, es necesario cambiar las formas de hacer antropología. Durante su largo trabajo solidario con las luchas indígenas por la recuperación de la tierra y de la historia, el antropólogo colombiano encontró que interpretaciones propias de guambianos y emberas, aquellas con los cuales comprendían, explicaban y transformaban su realidad, eran cosas del mundo (las piedras, la horqueta, el caracol, la flota mercante) y del diario vivir (el sombrero, el tejido en telar). De allí deriva la apuesta teórica y metodológica de recoger los conceptos en la vida y mantenerlos en ella. Los modos de trabajo que usó el autor fueron revolucionarios en su momento, como los mapas parlantes o los recorridos por el territorio. No obstante, algunos de ellos mantienen la separación entre el trabajo material y el trabajo intelectual, con la sospecha de que el segundo es de mejor calidad y, en última instancia, más productivo. Creemos que, en la actualidad, la mejor manera de acceder a esos conceptos vivos sin volverlos un problema solamente intelectual es ocupándonos en el trabajo material.

Nuestra propuesta surge de esfuerzos prolongados por comprender lo que nos ha enseñado el trabajo de campo en los Andes colombianos, así como de una incomodidad creciente — que no es solo nuestra (ver, por ejemplo, Bocarejo 2021) - con algunas prácticas que tienden a banalizar la tarea de la antropología. Lo anterior avanza sobre discusiones afines que hemos postulado en textos anteriores (Guzmán 2021; Guzmán y Martínez 2019; Suárez 2019, 2021a). 
También se nutre de los logros de Sebastián Anzola ([2017] 2020), con campesinos de Sucre (Cauca), y de Ana María Rodríguez (2020), con campesinos de San Bernardo (Cundinamarca). Nuestra propuesta no señala preguntas de investigación ni un horizonte teórico. Proponemos una manera de hacer trabajo de campo que, creemos, nos servirá para encontrar preguntas sensatas - que sean tan urgentes para quienes investigamos como para quienes nos educan en campo, preguntas cuyas respuestas nos ayuden a llevar la vida, preguntas que nos obliguen a acompañar la vida - y nos pondrá en posición de encontrar, también, otras formas de dar respuestas parciales. Para ello, dialogamos con planteamientos de Tim Ingold acerca de la tarea de la antropología y de los callejones, algunos sin salida, a los cuales nos enfrentamos en el mundo actual. Nos separamos de Ingold (2015a, 2017) en cuanto no creemos que la mejor alternativa para la antropología sea seguir las estrategias de estudio de los artistas. La gente que habita a ras del suelo, consciente de nuestra dependencia material de la tierra, nos enseña maneras también sensatas y en todos los aspectos mejor adaptadas a la vida que está siendo llevada. Una vida que, al no estar concluida, puede mejorar buscando nuevas formas o recuperando cosas que se han perdido.

\section{Dejarse enseñar para trabajar y trabajar para dejarse enseñar}

Lo primero será ir a vivir junto con las personas de las cuales esperamos aprender. No hay manera de aprender de ellas si no es en la vida que llevan. Vivir a ras del suelo para comenzar nuestra educación, en lugar de estudiar a un grupo humano para conocer sobre él. Se trata, como señala Ingold (2015a), de "estudiar con, ser instruidos por y aprender de" (221) la gente y su mundo, o del mundo y su gente.

Estudiar con ellos para aprender de todo lo que tienen para enseñar es aceptar una indagación que forma a sus practicantes. Acompañar el trabajo material educa tanto como asistir a clases en las universidades. Afirmamos con Tim Ingold (2015a, 2017, 2018a) que la investigación es un proceso educativo para quienes hacen antropología, no como transmisión de conocimiento para aquellos que no lo tienen, sino como una manera de brindar guía, críticas e inspiración en la búsqueda de cómo llevar la vida. Nosotros llamamos dejarse enseñar a la disposición necesaria para emprender una investigación que nos eduque en antropología. 
La educación que podemos recibir cuando hacemos trabajo de campo es afín a la noción de formación de Masschelein y Simons (2014). Los eventos formativos no son situaciones introspectivas o que requieran introspección, tampoco se producen a partir de la inculcación de ideas en la mente. Al contrario, son eventos que nos obligan, como aprendices, a salir de nosotros para estar en y con el mundo; nos obligan a exponernos o a salir afuera. Ex-ponernos, explica Masschelein (2005), es poner en riesgo nuestra posición, es estar fuera de posición, adoptar posturas siempre provisionales y móviles, que plantean preguntas y conducen a la indagación. Blanca Irreño y Orminso Acero, dos de nuestros maestros campesinos del centro de Colombia, denominan al trabajo de la tierra o al trabajo material y todos sus derivados "el trabajo de afuera” y "ponerle las costillas al sol”, respectivamente.

Para quienes estudiamos antropología no basta con salir de las aulas de clase hacia el terreno. La exposición requiere abandonar el amparo de los salones comunales, las escuelas rurales, los cabildos indígenas y las sedes de las organizaciones sociales o políticas. Nos exponemos cuando deliberadamente salimos de la posición que nos correspondería por ser investigadores: dirigiendo talleres, grupos focales o entrevistas semiestructuradas; haciendo las preguntas en conversaciones “espontáneas”; imponiendo, aunque con tono solícito, la realización de dibujos, cartografías sociales, tejidos, mandalas y otros productos de corte escolar (por eso a veces nos llaman profe en campo, aunque allí no dictamos clases). También resultamos expuestos cuando reconocemos que, aunque privilegiado por la academia, el género textual no es la única fuente de aprendizaje. No todo lo que se puede conocer proviene de un texto o, para el caso del campo, en forma de narrativas, oralidades o discursos, que se pueden "leer".

Creemos que todo trabajo material nos expone en el sentido que plantean Masschelein y Simons (2014) y, por lo tanto, tiene un enorme potencial de formación para las y los antropólogos. Cuando le ponemos las costillas al sol, le damos la cara a la tierra y podemos aprender algo de esa cercanía con el suelo y de la exposición a los rigores y bondades de la atmósfera. El “trabajo de afuera” disloca nuestra posición usual.

Según la definición de los campesinos en los Andes colombianos, el trabajo material es el trabajo que se ve (Anzola [2017] 2020) y supone un esfuerzo transformador de la materia en comida, abrigo o condiciones propicias para poder llevar la vida. Los campesinos ven el trabajo en las manos de quienes lo hacen y lo saben ver en las rondas en las cuales inspeccionan el trabajo hecho y por hacer. A estas salidas las llaman, en Colombia, rodiar, y rodiar es también un trabajo. El trabajo material es un adiestramiento en la transformación de aquello de lo que disponemos (incluidas las herramientas) para resolver los dilemas de la vida 
diaria (Rodríguez 2020). Pero es también una educación de la mirada que sabe reconocer tareas.

El trabajo que se ve es el que queda fijado, así sea fugazmente, con miras a continuar viviendo. No es un trabajo automático de nuestra voluntad volviéndose cosas: el trabajo supone acomodamientos y resistencias de la gente y de los materiales. Todo trabajo se acomoda a lo que pueden dar los materiales y a la gente con la que se trabaja. El trabajo material es el que se ve en lo que se ha hecho para vivir y el que hay que hacer para seguir viviendo. Y para eso la gente levanta casas, ara la tierra, cosecha, cocina, lava, barre, camina cargando la comida, conduce por carreteras destapadas, se monta en jeeps destartalados que obligan a agarrarse con fuerza de las varillas para no caerse.

Una vez expuestos, encontraremos que, como le enseñaron los indígenas tł̣chọ del norte de Canadá a Allice Legat (2012), el conocimiento no puede transmitirse verbalmente en fórmulas claras o aseveraciones organizadas como discursos. Al encontrarse en las habilidades y las capacidades de percepción, el conocimiento debe cultivarse y crecer dentro de uno. Consideremos los movimientos exactos que hacen que un envuelto de maíz tome la forma y la consistencia precisa, los que voltean la tierra con la azada para cosechar tubérculos sin dañarlos o los que reciben un peso y lo transportan. Ninguno se aprende como fuerza discursiva.

La destreza crece en nosotros por la fuerza de la tarea. De este modo, conforme crece nuestra capacidad de hacer y comprender lo que quieren enseñarnos, algunas cosas del mundo crecen en nosotros. Así empezamos a encontrar fascinantes las cosas que inquietan a las personas con quienes trabajamos. Nos importa aquello que reclama cuidado y atención en la vida diaria, que es lo mismo que reclama el cuidado y la atención de nuestros maestros y maestras. Así compartimos intereses. "Algo se transforma en un inter-esse (en algo que ya no es de nuestra propiedad sino es compartido entre nosotros)” (Masschelein y Simons 2014, 49).

Para que la investigación antropológica nos eduque habrá que hacerla con la firme intención de dejarnos enseñar de quienes trabajan. Aceptemos que sabemos muy poco o casi nada del mundo. La mayoría de las antropólogas y antropólogos no sabemos ni siquiera caminar, nos caemos, nos tropezamos, nos perdemos, no distinguimos las cercas, no sabemos reconocer los animales, los árboles, el ruido de las motos o los carros o de cada persona. Ferro (2021, 58-59) cuenta cómo los niños iku se reían de ella porque no sabía caminar: "tan vieja y todavía no camina”, le decían, hasta que, a fuerza de caminar todos los días con los tejidos y las chaquiras que le regalaron, un día se descubrió caminando correctamente: la Zati Adelaida le dijo: “Ahora sí está caminando”. 
Exponernos al mundo puede educarnos, hacer algo distinto de nosotros, pero es necesario un material dúctil o un terreno fértil para que esto ocurra. En nuestro caso, es una disposición como la que le enseñó un sabio a la antropóloga Ana María Palomo (2010) en San Bernardo del Viento: "el que sabe mucho aprende poco”. Hay que atender esta enseñanza y reconocer que no sabemos tanto como nos gustaría. La misma Ferro cuenta algo parecido cuando en su primer trabajo de campo, luego de un mes de estar importunando a sus maestros iku, tuvo que reconocer que no sabía qué hacía allá y ellos la recibieron porque vieron que tenía mucho que aprender $(2021,49)$. De hecho, emprendemos indagaciones acerca de la forma de vivir juntos para que quienes viven juntos y realmente conocen sean nuestros maestros y maestras.

\section{Contra el voluntarismo}

Cada vez que hemos acompañado las vidas campesinas e indígenas en nuestros trabajos de campo en los Andes colombianos, encontramos que las tareas que impone la vida diaria terminan convirtiéndose en nuestra obligación. Ingold (2018a, 28) explica que, al ser una cosa que debemos, una tarea no es propia, sino que pertenece a otros. En efecto, cuando indagamos acompañando la vida no se trata tanto de hacer lo que queremos como de hacer lo que debemos: en primer lugar, como deber adquirido o asignado; en segundo, porque siempre estaremos en deuda con quienes han participado de nuestra formación.

Una persona que tiene un deber no actúa motivada por libre albedrío, pero tampoco porque una autoridad superior le ordene; actúa porque el mundo interroga y demanda respuestas de quienes tienen la habilidad para contestar (Ingold 2018a). Respons-abilidad es la capacidad de responder, es lo que debe hacer quien sabe y puede hacer algo. Practicarla no es apegarse a un tratado preconcebido de normas éticas o políticas, sino el producto del cultivo mutuo de capacidades de respuesta y cuidado (Haraway [2016] 2019). No es un problema de voluntad o agencia, es la obligación debida a una habilidad que no nos pertenece. Esa habilidad, más que una particularidad del individuo, es muestra de una deuda impagable que solo puede restarse poniéndola en práctica.

El esfuerzo que suponen el trabajo material y el proceso educativo al que nos sometemos cuando hacemos trabajo de campo antropológico siempre se comparte con nuestros mentores. En ocasiones, es inevitable echar a perder algunas cosas, colmar la paciencia con preguntas irrelevantes (que en cualquier caso vamos a hacer y sirven para entender cuándo estamos siendo impertinentes); en esos momentos la gente detiene sus ocupaciones para señalar lo que considera 
importante que conozcamos o somos objeto de burlas y aprendemos a reírnos de nuestra torpeza. Cuando alcanzamos algún nivel aceptable de desempeño en las tareas, tienen en cuenta nuestros juicios y opiniones. Entonces recurrirán a nosotros para que desempeñemos alguna tarea de la que somos capaces y sabremos que la destreza en el trabajo es la que hace posible llevar la vida juntos. Nuestras maestras y maestros también aprenderán cosas que modificarán sus vidas. Nadie trabaja para sí mismo. Todo trabajo material hace posible la vida juntos.

Al asumir el trabajo material como imprescindible en la investigación antropológica, tal vez logremos renunciar a las demandas de la propia voluntad, la cual nos blinda, nos cierra en la mismidad e impide la transformación. Sin embargo, la derrota del voluntarismo por el reconocimiento de la fragilidad expuesta no debe confundirse con una disposición pasiva y condescendiente. La fragilidad expuesta logra firmeza y comprensión a medida que va ganando experiencia. La disposición pasiva no aprende y la condescendencia resulta un falso reconocimiento. Como plantea Donna Haraway (2002), es necesario tomar en serio la diferencia para lograr convivir con ella de cara al futuro: esto solo es posible llevando a cabo "un trabajo vulnerable, en el terreno, que combine agencias y formas de vida no armoniosas” (Haraway 2002, 39).

\section{Volvernos otros}

No podemos acompañar la vida de otros y seguir viviendo la vida nuestra de forma paralela. No podemos acompañar las vidas a ras del suelo más que con nuestras vidas. A medida que vamos resolviendo por qué aceptamos tareas, las herramientas y el mundo en el que trabajamos nos irán trabajando (ver Anzola [2017] 2020; Rodríguez 2020). Cuando nos esforzamos en el trabajo material, somos capaces de reconocer, con nuestros maestros y maestras, que solo somos una entre las muchas cosas del mundo, expuestas a la intemperie y al flujo del tiempo. Por eso, al compartir la vida en el trabajo, la tierra, las herramientas y los otros nos trabajan, de modo que podemos decir que nos debemos a ellos. Cuando volcamos nuestros esfuerzos en las mismas tareas de quienes nos adoptan como aprendices y nos alimentamos de los mismos frutos de ese trabajo para poder seguir haciéndolo, resultamos constituidos de otro modo. Como dice Luis Guillermo Vasco (2002, 472), al vivir la vida de los indios y tener los mismos problemas, uno se vuelve un poco como ellos y ellos un poco como uno. En este caso, volverse otro no es parte de una transustanciación mística o una impostación discursiva: es la evidencia más personal del esfuerzo por compartir la vida. Sería inocente suponer que por voluntad propia podemos renunciar a ser investigadores para 
convertirnos en indígenas. El trabajo de campo antropológico, como cualquier forma de investigación, ocurre en medio de una relación social con carácter objetivo, es decir, se encuentra "más allá de cualquier intencionalidad o voluntarismo personal o de grupo" (Vasco 2002, 434). Sin embargo, tener presente el privilegio que supone detentar el papel del investigador nos ayuda a reconocer los esfuerzos necesarios para modificar en la práctica dicha condición. Uno de esos esfuerzos es sumarnos como aprendices al trabajo material.

Nuestra formación y oficio como estudiantes, antropóloga y antropólogo, solo han sido posibles gracias a la gente con la que hemos trabajado en distintos lugares de los Andes colombianos, que siempre ha estado dispuesta a enseñar lo que sabe con seriedad y empeño y ha querido alimentarnos con los productos de su trabajo. Incluso, si no queremos aprender de ellos ni comer su comida, insisten. Quienes nos estamos educando como antropólogos y antropólogas, tanto en el terreno como en la universidad, debemos aceptar esas ocupaciones como lo que son: llenuras y trabajos, conocimiento y comida.

Como a los antropólogos Sebastián Anzola ([2017] 2020) y Ana María Rodríguez (2020), a nosotros también nos han enseñado que el trabajo material hace de un cierto modo a la gente: la tierra, sus elementos y las herramientas nos dan forma cuando llevamos la vida en su compañía. Solo acompañando el trabajo eventualmente seremos considerados personas. Ángel Quinayás, un viejo campesino del Cauca, le dijo a Sebastián Anzola ([2017] 2020) que hay que "humanarse a trabajar: [...] empezar a ser persona a través del trabajo” (8). No le estaba enseñando antropología, sino a vivir, pero eso es lo que aprende la antropología de sus maestras y maestros. Tanto Ángel Quinayás como Tim Ingold ([2015b] 2018) se refieren a ser humano como un verbo. No somos humanos terminados ni cosas dadas a priori; somos un constante hacerse o devenir con el mundo que no culminará mientras haya vida. Humanarse es ponerse al servicio de la gente, las herramientas, las cocinas y el terreno. A cambio, todos ellos ayudarán para que nosotros sigamos humanando, nos acompañarán en la vida. Humanarse es conservar el asombro y la perplejidad por la vida que crece, es buscar la vida y llevar la vida: la de los indios, la de los negros, la de los campesinos, la de la gente cuyo trabajo advierte que vivimos del suelo, del cual somos un crecimiento pasajero.

Al humanarnos, más que formación, sufriremos algunas deformidades que podríamos aceptar con gratitud: de nuestros pies, que agarrarán mucho del suelo al cual tendrán que aferrarse y por eso se agrandarán, se hincharán, sufrirán golpes o lastimaduras; de nuestras manos, que cambiarán de piel por las ampollas del trabajo con herramientas; de nuestros cuerpos, que engordarán o tomarán otra forma en el proceso constante de estar viviendo. 
Volvernos otras y otros inevitablemente cambia nuestro modo de hablar y de dirigirnos a las personas. No se trata de una imitación mal lograda de acentos o de la adopción de palabras, sino de una de las lecciones de respeto que la vida compartida en el trabajo nos enseña. Quizá nuestra mayor ganancia sea la sensatez que de este modo alcanzan las preguntas y los propósitos de indagación: ahora se orientarán hacia comprensiones y dejan de lado la pretensión de demostrar lo que ya sabemos. Así, serán innecesarios los términos grandilocuentes de la sociología espontánea (ver Bourdieu, Chamboredon y Passeron [1973] 2002; Vasco 2016). En cambio, nos esforzaremos por adoptar y comprender el lenguaje que emplean quienes viven a la altura del mundo, quienes son más conscientes de nuestra dependencia del suelo. Un lenguaje preciso y productor de comprensiones que debemos entender como una teoría en tensión de cada lugar.

Sebastián Anzola ([2017] 2020), por ejemplo, encontró que son constantes las categorías del crecimiento de la gente, la luna y las plantas en los Andes colombianos (creciente, merma, cambio y fuerza). Lo que no es constante es su aplicación, sobre la cual, como sobre todo lo importante, hay grandes discusiones, que en este caso dejan ver que se trata de una teoría en tensión para conservar la vida: no es un “conocimiento ancestral” (ver Ingold 2012) aplicable de una vez y para siempre de la misma forma. Para comprender esas disputas sobre lo que crece y cómo lo hace, debemos acompañar la vida.

También se transformarán de manera dramática nuestras certezas de investigación. Todo puede ser transformado en la acción; por eso la formación en el trabajo que acompaña la vida es apertura del mundo que no engrosa un acervo de ideas y "datos” en nuestra "mente”, sino que crece con las labores materiales que acometemos. Con estas, nuestras posibilidades de acción y percepción pueden extenderse ampliando a su vez el mundo mismo.

\section{El mundo también enseña}

Llamamos mundo al suelo y a todas las cosas que ocupan a la gente y la obligan a aceptar sus presencias (desde lo que pasa en la atmósfera hasta lo que vive bajo tierra). El mundo es objeto de reconocimiento, estudio y cuidado por la gente. Lo ocupan las entidades atmosféricas, los crecimientos desde el suelo que unas veces llamamos plantas, otras veces animales y otras veces construcciones. El mundo no es un escenario sobre el cual transcurre la vida humana, es de donde salen ella y todo lo que la sostiene (Ingold [2015b] 2018). Y, para sostenerse, las vidas humanas trabajan. El trabajo hace nuestra comprensión del mundo y es la razón de ese conocimiento. Es, además, lo que lleva la vida hacia adelante. 
Se trata más de vivir atentos a las exigencias de la vida y el mundo que de poner en práctica máximas acumuladas u ocultas en alguna tradición, incluso si esta es académica. Por ejemplo, en las vidas campesinas, el terreno enseña. Ellos saben que el mundo y el trabajo imponen seguir instrucciones que, al seguirse, se muestran/se revelan como ineludibles.

La disposición expuesta y frágil también sirve para someterse al terreno, pues es él quien dicta qué se puede hacer y qué no. Al terreno le es indiferente si aceptamos su guía o no. Nos obliga a estar atentos a la superficie del suelo, a las condiciones del tiempo, a las cosas que crecen y a los sonidos que van y vienen. Cuando el terreno es inclinado nos pide pararnos duro, oponiéndonos a la fuerza de la pendiente e inclinarnos, algunas veces casi al nivel del suelo, para no caer (Guzmán Peñuela 2021).

Mientras andemos expuestos, el mundo se abrirá enseñando procesos que hasta el momento no habíamos percibido. Este aprendizaje empezará a formar parte de nosotros y es en lo que nos debemos esforzar para que otros lo comprendan: tanto nuestros mentores como nuestros lectores cuando tengamos que escribir. Estos eventos resultan formativos porque nos moldean, le dan forma a nuestra comprensión y son el conocimiento que alcanzamos de la vida. Junto a la gente que trabaja aprendemos que el mundo, los materiales y las sustancias se abren y revelan sus sabidurías. Es un proceso lento, en el que nuestros maestros son el mundo y la gente.

El conocimiento del mundo y de la historia son una misma cosa para quienes trabajan la tierra o con sus materiales. No solo porque los hechos se quedan fijados en los lugares, sino porque caminando el mundo a pie limpio se recorre y se cuenta la historia (Aranda, Dagua y Vasco 1993; Urdaneta 1991). También porque andar a pie a la altura del mundo es la única forma de conocer a los seres en su vida constante (Ingold [2015b] 2018).

Más pronto que tarde notamos que el trabajo del mundo en nosotros no tiene cuándo terminar, por eso es necesario volver y volver a volver al terreno para empezar a comprender en una de esas vueltas. Como nos enseña Claudia Platarrueda (2018), se trata de ir y volver y quedarse yendo: la investigación que acompaña la vida es un largo proceso, que no encuentra comodidad dentro de las oficinas o en las aulas de clase, exclusivamente. Se sabe incompleta y con el compromiso de regresar.

Optar por la vía de dejarnos enseñar, trabajar y compartir intereses indefectiblemente nos conduce al abandono de los propósitos de documentación con los que redactamos originalmente nuestros proyectos de investigación. Además del trabajo material, hay cosas que tienen que hacerse: hay que hacer arreglos en la casa, hay que bajar frutas de los palos, hay que buscar a la gallina que se 
ha ido a poner los huevos al monte, hay que hacer la limpieza, hay que devolver visitas, hay que salir al pueblo, hay que ir a alguna misa o hay que ir al cementerio. Se vuelve nuestro deber acompañar estas tareas y ello impide dedicar los días a hacer preguntas que solo atañen a una labor documental. La recolección de información por mandato de tal o cual proyecto de investigación nos aísla de la vida, nos priva de compartir intereses.

No podríamos dejar de reconocer la inagotable deuda que tenemos con quienes nos educan y las responsabilidades que trae consigo el esfuerzo de investigar acompañando la vida: seamos útiles para tareas concretas; procuremos dañar muy poco en el proceso de aprendizaje y, siempre que sea necesario, asumamos los costos por los daños debidos a nuestra incompetencia; tomemos en serio las tareas que nos sean encomendadas; tratemos con respeto y como conocimiento (no como "creencias" o como discursos) las certezas de la gente; permanezcamos solamente en los lugares a los cuales hemos sido invitados o en los cuales tenemos permiso; cumplamos nuestra palabra; evitemos convertirnos en una carga; sobre todo, entendamos que lo anterior no es opcional.

\section{¿Por qué investigar de otro modo?}

En las universidades y centros de investigación incomodan las desigualdades y solemos hacer de ellas el centro teórico de nuestras reflexiones. Sin embargo, no parecen incomodar de igual manera las técnicas de campo o el modo de hacer las investigaciones. No parecemos notar que la mayoría de esos modos de hacer se originaron en la desigualdad y tienden a perpetuarla. Nuestros protocolos de investigación se conforman con instrumentos para la recopilación, la recolección o la recuperación de datos, que suponemos preñados de significados, representaciones, relaciones profundas o dispositivos como indicios o síntomas a la espera de ser desentrañados (cfr. Geertz [1972a] 2003, [1972b] 2003; Ginzburg 2008).

En esos casos, no suele interesar tanto lo que los investigados digan como lo que sus narrativas dicen del tipo de gente que ellos son o de mecanismos que están más allá de su comprensión (desde los sustratos culturales profundos hasta los discursos de la dominación). Vasco (2002) se refiere a la poca confianza de los antropólogos en el conocimiento que las sociedades indígenas tienen de sí mismas, de su entorno, de sus formas de vida y de las leyes que las rigen. En ese sentido el autor parafrasea a Malinowski: "la clave para interpretar la cultura no la pueden ofrecer los informadores nativos porque ellos la desconocen 
conscientemente. Es más adecuada la visión que ofrece el antropólogo" (Vasco 2002, 442). Con esta certeza, el único camino que queda para la antropología es reducir a las personas a ser objetos del conocimiento de alguien más. La autoridad de los antropólogos se encuentra, además de en sus credenciales, en su perspectiva. Es decir, en la posibilidad de adoptar una posición suficientemente distante para observar a sus objetos desde otro ángulo, uno privilegiado; cenital, si es posible. No obstante, Masschelein (2005) explica que la observación en el sobrevuelo es desapegada, aséptica y solo permite obtener impresiones visuales de un camino, por ejemplo. Lo contrario es renunciar a la vista panorámica para recorrer el camino a pie. De este modo el sendero se impone con cierta autoridad, es experimentado, es vivido a ras del suelo.

Siempre que busquemos estudiar $a$ la gente o a los fenómenos sociales o a las culturas, estaremos haciéndolos objetos de nuestra voluntad (en muchos casos, una voluntad altruista o consagrada al desarrollo de las ciencias sociales), pues hacemos de su vida y de todo lo que nos confiaron la materia prima de un trabajo más elaborado (extractivismo capitalista 1.0), que, al parecer, vale más la pena que sea conocido. Por eso, esta propuesta no busca nada más que lo que nos quieran enseñar; no persigue estudiar a la gente o a su cultura, sino aprender.

Ingold ([2018b] 2020) señala que, cuando asumimos las enseñanzas y conocimientos de los indígenas como síntomas de algo más - probablemente de la mano oculta de la cultura, que conduce las acciones y pensamientos de la gente sin que ella lo sepa-, no los estamos tomando en serio. La creencia antropológica en que la vida de la gente con la que trabajamos se rige por la repetición autómata de culturas o tradiciones no permite que madure en quien investiga el respeto por el conocimiento de la gente corriente. Al sumarnos a la práctica de las labores, incluso las más comunes — pues "el saber es un saber hacer y el conocer lo es para vivir” (Vasco 2002, 449) —, nos veremos obligados a prestar atención a los seres humanos, a los no humanos y al mundo de una manera diferente. De ese modo, necesariamente cuestionamos lo que teníamos por cierto y crecen en nosotros preguntas fundamentales acerca del mundo y de la vida misma.

No es que creamos con ingenuidad en una solución indígena para todos los problemas de la humanidad, pero sus formas de vida, con seguridad, nos ayudarán a imaginar, a todos, alternativas para el modo destructivo en que vivimos. Hemos aprendido de Haraway (2019) que es preciso imaginar modos de vivir y morir juntos, de una manera más responsable y justa.

Otras veces el comprensible rechazo a reproducir la desigualdad termina por ocasionar renuncias definitivas a una indagación transformadora para quienes hacen antropología. De este modo, circunstancialmente ejecutamos las tareas colaborativas que requieren las organizaciones, tales como relatorías, 
transcripciones o apoyo logístico. En estos casos no se puede decir que se trate de un trabajo que saca a los investigadores de su posición habitual ni que se aprende a hacer de modos distintos. Aunque uno siempre da lo que sabe porque no puede ser de otro modo, esto no debería ser la excusa para no aprender otras formas de llevar la vida y para, eventualmente, transformar los supuestos de la antropología. Cuando renunciamos a participar en la vida también renunciamos a abrir la investigación.

Trabajar con la gente y acompañar en la vida nos permite ir hacia un lugar distinto al trabajo con narrativas. Somos conscientes de que no todo puede ser dicho. Eso no es lo mismo que suponer que la gente no entienda lo que hace, sino que hay comprensiones que son casi imposibles de explicar con palabras. Que uno no pueda hablar de algunas de las cosas que hace no quiere decir que no sepa cómo hacerlas. En el trabajo material eso es más que notorio porque lo que debemos aprender son movimientos, técnicas corporales, olfato, ojo, todas esas cosas que se aprenden haciendo. El lenguaje no agota la experiencia de vivir, siempre en proceso, en un mundo igualmente inacabado.

No negamos que la conversación entre pares sea un horizonte legítimo e ideal para la antropología. Dudamos que la conversación sea entre pares si lo que nos cuentan, vemos y hacemos en campo no es algo que nos empeñamos en comprender y practicar hasta aprenderlo (lo que haríamos si lo asumiéramos como un conocimiento valioso para la vida), sino que lo tomamos como insumo de análisis para decir algo más de la vida de esa gente. No podemos aprender de ellos a menos que nos interese lo que saben. A los expertos en la tierra les preguntamos por sus identidades, a quienes conocen los ciclos del agua les queremos analizar los discursos, a quienes tienen algo para enseñar acerca de cómo se puede vivir con otras especies les analizamos las representaciones. De ese modo, quienes nos acogen en campo no pueden ser nuestros maestros. Mucho menos podremos aprender del entorno si no somos guiados por quienes conocen más que nosotros. Tomar en serio, en este contexto, supone un esfuerzo por comprender de qué manera lo que dicen y hacen les permite llevar la vida y nos puede servir a todos para seguir viviendo.

Por estas razones creemos necesario explorar modos distintos de conocer y seguir haciendo antropología. La fortaleza de nuestra disciplina ha estado siempre en el buen juicio que enseña compartir la vida de la gente. Malinowski ([1922] 2001), cuando invitaba a fijarse en "lo imponderable de la vida real", no se refería a otra cosa, sino a esa apertura que reconoce la ignorancia pero está atenta. Cualquier persona que durante un trabajo de campo de duración respetable ha llegado a apreciar y a ser apreciada por las personas con las que trabaja sabe que los mejores frutos de esas indagaciones son imponderables y que eso 
imponderable nos ata a esas vidas y, muchas veces, nos da los argumentos que esgrimimos en textos y conferencias. Esta propuesta es un producto en proceso de la forma en que hemos encontrado que podríamos llevar adelante la lucha necesaria contra las desigualdades.

\section{Contra los finales cerrados}

Todo lo dicho hasta aquí contradice los protocolos usuales de investigación. Los esquemas y marcos lógicos de los proyectos de investigación están obsesionados con la finalización de la investigación y con los productos. Se esfuerzan por lograr claridad en las metas, los objetivos, los cronogramas y las fechas límite. Estudiantes y profesionales, en todas las instancias académicas, se ven obligados a acotar, delimitar y delinear con precisión sus posibles resultados y hallazgos. Las metodologías, abundantes en procedimientos, técnicas y tecnologías para la extracción de información, valoran tanto la economía del tiempo de los investigadores que terminan convirtiendo los medios en fines. Lo importante es la elaboración de un informe, también llamado producto. Se trata de un modo industrializado de producción de conocimiento que suele acompañarse de escrituras agroindustriales (ver Ferro 2021; Taussig 2015).

Comprometerse con ese modo de producción nos aleja del propósito de acompañar la vida en el trabajo y de dejarnos enseñar que hemos expuesto. Acompañar la vida trabajando exige lo contrario: acatar la autoridad de nuestros maestros, el terreno y la gente, y asumir las responsabilidades surgidas de la vida compartida sin tener, necesariamente, que saber a dónde nos pueda conducir.

¿Cómo podemos saber lo que vamos a conseguir de un aprendizaje que aún no ha empezado? Esa pretensión le atribuye un exceso de agencia a nuestra voluntad. En la vida las cosas no pasan como queremos, pasan como pasan. Y puede que por exceso de voluntad no podamos advertir lo que sucede. Imponer nuestros objetivos es imponer nuestra condición dominante e implica un alto costo: sacrificamos nuestra educación y la transformación de las relaciones que hacen posible la antropología como una empresa éticamente comprometida. Podríamos hacer algo más que los ejercicios documentales que parecen caracterizar a la disciplina. Tan atentos al pasado, no parecemos advertir la vida como está siendo. Muchos de estos ejercicios de recolección de datos tienen como único fin producir o demostrar resultados prefabricados en la forma de artículos o monografías (ver Bocarejo 2021; Ingold 2017, 153). Supeditar el curso que de forma 
emergente toman las indagaciones que acompañan la vida a la persecución policíaca de los objetivos de descripción impide aprender de la gente y del mundo.

En el centro de Colombia se habla de "tener destino" como de tener un deber por realizar. Se trata de ser útiles, de estar ocupados en una labor o de desarrollar cualquier trabajo o tarea. Tener destino no se refiere a la meta o a la finalidad de una acción. No es una tarea que deba terminarse, sino una tarea que hay que hacer y que tocará seguir haciendo. Podríamos acometer la investigación como una serie de tareas que no encuentran razón de ser en el resultado final, sino en la realización de lo que es necesario para seguir llevando la vida. Investigaciones que no se someten a un resultado final o a unos objetivos, sino que se conforman con estar haciéndose. En el centro de Colombia la gente encuentra bastante satisfacción en tener trabajo, no en terminarlo. Si termináramos todos nuestros trabajos, no tendríamos cómo vivir.

Esto tiene algo que enseñarnos acerca de la investigación que acompaña la vida y de la usual subordinación de la experiencia en el terreno al resultado final. La lógica del método está trastocada porque si se necesita campo debe ser porque no se sabe lo que se va a encontrar. Al fijar la dupla "objetivos-resultados esperados”, explica Ingold (2018a), estamos empezando por el final o, como dirían en el centro de Colombia, "estamos queriendo montar las mulas antes de ensillar”. ¿No sería mejor empezar fijando un punto de partida que contemple el trabajo de campo como un trabajo y un proceso? ¿No sería mejor caminar con la tarea, el encargo, la labor de aprender a ver y a oír, en lugar de llegar a una meta? (Masschelein 2005, 7). El único encargo es el de acompañar a la vida y comprometerse con las ocupaciones que la hacen posible. Y si no se llega a un final claro debe ser porque la vida quiere seguir viviéndose y nuestras investigaciones deberían renunciar a agotarla en explicaciones en exceso coherentes o sin cabos sueltos.

Hace poco Laura Chaustre (2020) nos enseñó que las respuestas que afanosamente buscamos para cada uno de los interrogantes que el mundo y la vida nos plantean son cierres fabricados con certezas engañosas. Estos cierres nos brindan la ilusión de haber alcanzado finales redondos para preguntas que podrían ser una espiral sin fin. Tomémonos en serio la tarea de aprender de la gente. A la gente comúnmente le gusta enseñarles a quienes prestan atención. Tal vez esto se deba a que saben que el conocimiento para vivir debe criarse o crecer como la vida misma y a que reconocemos que la vida no puede ser de uno. Debe ser cuidada, llevada, alimentada y trabajada. 


\section{Referencias}

Anzola, Juan Sebastián. (2017) 2020. Uno hace la finca y la finca lo hace a uno: trabajo, conocimiento y organización campesina en Sucre, Cauca. Bogotá; Santander de Quilichao: Editorial Gente Nueva.

Aranda, Misael, Avelino Dagua Hurtado y Luis Guillermo Vasco. 1993. "En el segundo día, la gente grande (numisak) sembró la autoridad y las plantas y, con su jugo, bebió el sentido”. En Encrucijadas de Colombia amerindia, editado por François Correa, 9-48. Bogotá: Instituto Colombiano de Antropología.

Arendt, Hannah. (1958) 2009. La condición humana. Traducción de Manuel Cruz. Buenos Aires: Ediciones Paidós.

Asociación Colombiana de Antropología, ed. 2021. La etnografía: problemas y soluciones. Bogotá: Asociación Colombiana de Antropología.

Bocarejo Suescún, Diana. 2021. "Etnografía: entre la ambigüedad de las prácticas, el movimiento y la fragilidad”. En Asociación Colombiana de Antropología 2021, 13-41.

Bourdieu, Pierre, Jean-Claude Chamboredon y Jean-Claude Passeron. (1973) 2002. El oficio de sociólogo. Traducción de Fernando Hugo Azcurra. Buenos Aires: Siglo XXI Editores Argentina.

Chaustre Fandiño, Laura. 2020. "Enseñarse a tomar en serio. Risas, personas y trabajos en los Andes colombianos". Conferencia en Conversaciones sobre Asuntos de Campo, quinta temporada. Consultado el 5 de septiembre de 2021. https://www.youtube.com/ watch?v=NKqRsXwU8g0\&t=2256s

Ferro Umaña, María del Rosario. 2021. "Tres anotaciones sobre la etnografía desde mi experiencia como antropóloga en Colombia”. En Asociación Colombiana de Antropología 2021, 43-75.

Geertz, Clifford. (1972a) 2003. "Descripción densa: hacia una teoría interpretativa de la cultura”. En La interpretación de las culturas, 17-40. Traducción de Alberto L. Bixio. Barcelona: Gedisa.

—. (1972b) 2003. "Juego profundo: notas sobre la riña de gallos en Bali”. En La interpretación de las culturas, 339-372. Traducción de Alberto L. Bixio. Barcelona: Gedisa.

Ginzburg, Carlo. 2008. "Indicios. Raíces de un paradigma de inferencias indiciales”. En Mitos, emblemas, indicios. Morfología e historia, 185-239. Barcelona: Gedisa.

Guzmán, Laura. 2021. "Buscar la forma: ir sometiéndose y andar toriando caminos en el norte del Tolima, Colombia”. Revista de Antropología y Sociología Virajes (RASV) 23 (1): 65-99. https://doi.org/10.17151/rasv.2021.23.1.4

Guzmán, Laura y Natalia Martínez. 2019. "Entrar y salir de la tierra. Un evento de la fuerza reproductora en el suroccidente andino colombiano”. En Cosas vivas. Antropología de objetos, sustancias y potencias, editado por Luis Alberto Suárez Guava, 207-246. Bogotá: Pontificia Universidad Javeriana. 
Haraway, Donna. 2002. The companion species manifesto: dogs, people and significant otherness. Chicago: Prickly Paradigm Press.

-. (2016) 2019. Seguir con el problema. Generar parentesco en el Chthuluceno. Traducción de H. Torres. Bilbao: Consonni.

Ingold, Tim. 2011. Being alive: essays on movement, knowledge and description. Abingdon: Routledge.

-. 2012. "Contra la cultura, abrazando la vida”. En Ambientes para la vida. Conversaciones sobre humanidad, conocimiento y antropología, editado por Tim Ingold, 35-53. Montevideo: Ediciones Trilce.

-. 2015a. "Conociendo desde dentro: reconfigurando las relaciones entre la antropología y la etnografía”. Etnografías Contemporáneas 2 (2): 218-230. https://revistasacademicas.unsam.edu.ar/index.php/etnocontemp/article/view/410

—. (2015b) 2018. La vida de las líneas. Traducción de Ana Stevenson. Santiago de Chile: Ediciones Universidad Alberto Hurtado.

—. 2017. “¡Suficiente con la etnografía!”. Revista Colombiana de Antropología 53 (2): 143-159. https://doi.org/10.22380/2539472X.120

—. 2018a. Anthropology and/as education. Nueva York: Routledge.

—. (2018b) 2020. Antropología. ¿Por qué importa? Traducción de Esther Gómez Parro. Madrid: Alianza Editorial.

Legat, Allice. 2012. Walking the land, feeding the fire: knowledge and stewardship among the ttıcho dene. Tucson: The University of Arizona Press.

Malinowski, Bronisław. (1922) 2001. Los argonautas del Pacífico Occidental. Comercio y aventura entre los indígenas de la Nueva Guinea melanésica. Traducción de Antonio Desmonts. Barcelona: Ediciones Península.

Marx, Karl y Friedrich Engels. (1845) 1968. La ideología alemana: crítica de la novísima filosofía alemana en las personas de sus representantes Feuerbach, B. Bauer y Stirner y el socialismo alemán en las de sus diferentes profetas. Traducción de Wenceslao Roces. Montevideo: Pueblos Unidos.

Masschelein, Jan. 2005. “E-ducar la mirada. La necesidad de una pedagogía pobre”. En Educar la mirada. Políticas y pedagogías de la imagen, compilado por Inés Dussel y Daniela Gutiérrez, 295-310. Buenos Aires: Ediciones Manantial.

Masschelein, Jan y Marteen Simons. 2014. En defensa de la escuela. Una cuestión pública. Traducción de Antonio Francisco Rodríguez Esteban. Buenos Aires: Miño y Dávila Editores.

Palomo, Ana María. 2010. “Cuerpos devorados. Consumo, brujería y canibalismo en San Bernardo del Viento”. Tesis de pregrado, Departamento de Antropología, Universidad Nacional de Colombia, Bogotá.

Platarrueda Vanegas, Claudia Patricia. 2018. "Ir y volver y quedarse yendo. Motivaciones para el campo". Conferencia presentada en Conversaciones sobre Asuntos de Campo, tercera temporada, Universidad de Caldas, Manizales, 28 de septiembre. 
Rodríguez, Ana María. 2020. "Resolver y andar en junta en un mundo que torea. Antropología de la vida campesina en San Bernardo, Cundinamarca”. Tesis de pregrado, Departamento de Antropología, Pontificia Universidad Javeriana, Bogotá.

Saade, Marta. 2019. “'Aquí estamos, aquí hemos estado’. Historias de mujeres indígenas en el suroccidente colombiano”. En Cultura y poder: reflexiones interdisciplinarias en ciencias sociales, editado por Juan David Delgado Rozo, 33-64. Bogotá: Editorial Universidad Externado de Colombia.

Suárez Guava, Luis Alberto. 2019. "La vida de las cosas y las formas del conocimiento: desafíos para hacer otras antropologías”. En Cosas vivas. Antropología de objetos, sustancias y potencias, editado por Luis Alberto Suárez Guava, 19-48. Bogotá: Editorial Pontificia Universidad Javeriana.

-. 2021a. "Una antropología con las manos sucias y la barriga llena. Propuesta de trabajo seguida de muchos rayes”. En Asociación Colombiana de Antropología 2021, 76-116.

-. 2021b. "Guacas: las ocupaciones crecientes de los Andes colombianos (una antropología a ras del suelo)”. Tesis doctoral, Departamento de Antropología, Universidad Nacional de Colombia, Bogotá.

Taussig, Michael. 2015. The corn wolf. Londres: University of Chicago Press.

Urdaneta Franco, Martha. 1991. "Huellas de Pishau en el resguardo de guambia: ensayando caminos para su estudio”. Boletín Museo del Oro 31: 3-29. https://publicaciones.banrepcultural.org/index.php/bmo/article/view/7018/7264

Vasco, Luis Guillermo. 2002. Entre selva y páramo. Viviendo y pensando la lucha india. Bogotá: Instituto Colombiano de Antropología e Historia.

-. 2016. "Desechar los conceptos en la vida". Conferencia presentada en la Pontificia Universidad Javeriana, Bogotá. Transcripción de Jazmín Rocío Pabón. http://www.luguiva.net/ articulos/detalle. aspx?id=100 


\title{
El oficio de la antropología y el trabajo de humanarse
}

\author{
Diego Cagüeñas* \\ Universidad Icesi, Colombia
}

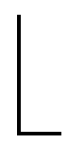

eo en el artículo de Laura Guzmán y Luis Alberto Suárez la manifestación de un malestar. O malestares. Malestar con el estado actual del oficio de la antropología, dominado por informes y métodos instrumentales; malestar, este más callado, con la vida citadina, alejada del trabajo de la tierra y la producción de la vida. Ambos malestares resienten el entorpecimiento del trabajo de humanarse. Los comparto en parte y no los creo exclusivos de la antropología. En atención al breve espacio del que dispongo, me concentraré en un par de formulaciones que se me antojan problemáticas, para luego cerrar con unas palabras acerca del concepto de humanarse, no sin antes señalar la importancia de este tipo de reflexiones que nos proponen los autores, en las que encuentro un síntoma de la vitalidad de un oficio que no cesa de pensarse a sí mismo.

Guzmán y Suárez nos invitan a considerar una forma de hacer antropología que estiman más fecunda y justa, la cual consiste en acompañar el trabajo material, esto es, aprender, ejercer y, quizás, encarnar el quehacer de aquellas personas cuyas labores "permiten que la vida siga sucediendo". En contraste con el trabajo de campo que hace énfasis en la observación y el registro de las actividades de aquellos que se consideran "objeto de estudio", acompañar la vida nos permitiría aprender algo más valioso y que no se podría aprender de otro modo. Dado que la propuesta concierne al trabajo etnográfico relacionado con oficios que "llaman la atención sobre nuestra dependencia del suelo", podríamos aprender acerca de la dependencia fundamental de la vida humana frente a otras formas de vida, así como de nuestra exposición a "la intemperie y al flujo del tiempo”. A través de la repetición del trabajo con el suelo que se nos resiste, aprenderíamos sobre lo que es una buena vida y una vida buena. Una propuesta sugerente, sin duda. Y, sin embargo, no puedo dejar de preguntarme cuál sería entonces la naturaleza del saber antropológico.

dcaguenas@icesi.edu.co / https://orcid.org/0000-0001-5274-5336 
Me explico. Supongamos que nos dejamos enseñar cómo cultivar una vida vegetal particular. Ello solo puede llegar a feliz término si nos hacemos más atentos a las características del suelo, a los ires y venires de aguas y vientos. Nos habremos transformado, pues seremos mejores cultivadores. Pero eso no es todo. Hemos aprendido algo más, hemos aprendido nuestro justo lugar en el entramado cósmico, con lo cual, es de esperar, dejaremos de perpetuar injusticias y exclusiones. Aclaran los autores que no se trata de una suerte de experiencia mística, sino del resultado del trabajo repetido, mancomunado y bien hecho. Esto evitaría que hagamos uso de lo aprendido como "insumo de análisis para decir algo más de la vida de esa gente”. Convengamos que sea así. ¿Pero, de ser posible, esto es suficiente?, ¿cómo no decir “algo más”?, ¿ese “algo más” que podríamos decir antropólogos y antropólogas es necesariamente fruto de una relación de subordinación y de explotación de otras vidas y saberes?

Comparto con los autores que la mayoría de nuestros modos de hacer se originaron en la desigualdad y tienden a perpetuarla. ¿Cómo imaginar otros modos que no carguen ese lastre heredado sin que por ello se disuelva el oficio de la antropología? Los autores confían en que podemos aprender de la vida, en lugar de "documentar o elaborar apreciaciones abstractas de una vida que ya no es”. No creo que esto sea posible. Quizás porque nunca he sentido enemistad por la abstracción, o mejor, la producción de conceptos. Que aprender de la vida nos haga mejores personas y mejores antropólogos y antropólogas es un deseo loable. Mas no creo que ello nos exima del trabajo del pensamiento, el cual, siempre parte de la vida, suele pasar después. Lo que no quiere decir que la vida ya no sea, sino que la vida puede ser pensada porque pensar es un modo de hacer enteramente arraigado en ella. "El empirismo es el misticismo del concepto”, escribió alguna vez Deleuze. Los conceptos son las cosas mismas porque pensar es producir mundos. Mundo, vida y la vida son conceptos particularmente poderosos debido a las copiosas conexiones que continúan permitiendo. Sin abstracción no hay cosecha.

Ahora bien, el malestar que sí comparto con Guzmán y Suárez tiene que ver con el "modo industrializado de producción de conocimiento que suele acompañarse de escrituras agroindustriales”. El problema que percibo en la antropología contemporánea, más que con el recurso a la abstracción, tiene que ver con su predictibilidad. Buena parte de lo que hacen las ciencias sociales hoy es poco más que la "recolección de datos cuyo único fin [es] la producción de resultados o la demostración de resultados prefabricados”. El guion, tantas veces repetido, es ya familiar en demasía: una comunidad minoritaria en algún sentido es "invisibilizada” por una entelequia mayor, cuyo nombre es más o menos intercambiable: 
capitalismo, racismo, neoliberalismo, extractivismo, y así... Los sospechosos de siempre. "Visibilizar" es el verbo más usado para describir la parte jugada por el antropólogo o la antropóloga en esta operación de previsible desenmascaramiento. Lo que se "visibiliza" es lo que se tenía por cierto de antemano (o lo que pedía el grant, que viene a ser más o menos lo mismo). Esto es mala abstracción. Mala porque suele desatender lo ocurrido durante el trabajo de campo a cambio de disfrazar como conclusiones lo que en realidad son presupuestos. Mala abstracción porque el concepto siempre tiene una raigambre a partir de la cual viaja y produce nuevas conexiones, nuevos entendimientos, nuevas conversaciones. La escritura agroindustrial es el desfallecimiento del concepto.

De ahí la importancia del trabajo de humanarse. Desearía que humanarse llegara a ser un concepto habitual pues su raigambre es íntegra y fértil. Los autores explican que consiste en "conservar el asombro y la perplejidad por la vida que crece”. Es un concepto bello pues nombra algo que solo se puede hacer junto a otros y que no se puede hacer de otra manera. No son las palabras de las que Guzmán y Suárez se valen, pero creo que en este llamado a humanarnos abogan por una antropología más experimental, más preocupada por el proceso, por el hacer, que por el resultado. Una antropología más cercana a las vicisitudes de la vida, a los azares del trabajo. Una antropología que se escriba durante y después, no antes. El asombro no es posible si se sabe por adelantado lo que se quiere encontrar, si la pregunta ya ha dividido el mundo en opresores y oprimidos, si la indignación —casi siempre justa— toma el lugar del pensar. El asombro se aviene mejor al ensayo; a la escritura abierta que busca, con curiosidad incansable, lo impensado. El paper, por el contrario, suele corroborar. Se ha convertido en herramienta de señalamiento y denuncia; lo que no está mal, pero es insuficiente. Aún queda por hacerse el trabajo de comprender, esto es, de humanarse. Siempre habrá algo más que decir. La pasión por las vidas que hacen posible la vida y el acompañamiento de la vida material, en la que se han embarcado Guzmán y Suárez, nos sirven para recordar la importancia del trabajo de humanarse. Que no es poco. 


\section{Sobre lo que implica aprender de los otros para la antropología}

Ana Padawer ${ }^{\star}$

Universidad de Buenos Aires, Argentina

$\longleftarrow$

a tradición antropológica de la investigación de campo ha proporcionado a las ciencias sociales una originalidad epistemológica: la producción de conocimiento mediante la tensión permanente entre el compromiso y el distanciamiento, expresada en el plano técnico mediante la observación participante (Batallán y García 1992). En la segunda mitad del siglo XX, la antropología latinoamericana, así como otras del sur global, ha logrado un desarrollo considerable de temas y reflexiones metodológicas que le permiten revisar este paradigma debido a la vecindad sociopolítica con los sujetos con quienes trabaja, de manera que hacer antropología en nuestros países resulta un ejercicio de cociudadanía (Jimeno 2005) —aun cuando constantemente miramos la producción de los países centrales-.

El artículo de Guzmán Peñuela y Suárez Guava comparte esa preocupación epistemológica y política por reconocer la importancia de nuestros interlocutores en la producción de conocimiento antropológico, ya que proponen que el trabajo de campo etnográfico debería realizarse "acompañando la vida en el trabajo material". Esto para aprender genuinamente de una alteridad subalterna: "vidas a ras del suelo por su concrescencia con la tierra, el aire, el agua y todos los materiales del trabajo".

Desde hace varias décadas se ha planteado la idea del antropólogo/a como aprendiz (Coy 1989). Además, atendiendo a que todo conocimiento es situado (Lave y Wenger 1991), parece acertado que, para reconstruir cómo hacen las cosas nuestros interlocutores, compartamos sus quehaceres cotidianos. No obstante, siguiendo esa idea de la situacionalidad del conocimiento, creo que es igualmente importante enfatizar que el conocimiento antropológico surge de nuestras propias preguntas que, al acercarnos a nuestros interlocutores y aprender de ellos mediante el hacer, podemos revisar y, de esa manera, entender de forma más compleja aquello que nos habíamos preguntado (Bourdieu y Wacquant 1995).

* $\quad$ apadawer66@gmail.com / https://orcid.org/0000-0003-4024-4723 
Guzmán Peñuela y Suárez Guava proponen “acompañar esta vida de ocupaciones y desocupaciones”, ya que "las tareas irán creciendo en nosotros gracias a las repeticiones siempre necesarias del trabajo”. Esta idea de las habilidades que crecen siguiendo los senderos de los expertos (Ingold 2002) es muy poderosa para orientar trabajos etnográficos más horizontales, al compartir la premisa ética de que la información debe ser un regalo, no un botín de guerra resultado de relaciones de poder y autoridad implícitas en la propia práctica (Díaz de Rada 2010).

Aunque la forma en que hacemos trabajo de campo es un asunto ineludible en las consideraciones acerca de la validez de lo que hacemos, es igualmente relevante reconocer y trabajar reflexivamente sobre cómo nuestras preguntas, generadas en nuestra cotidianidad, nos orientan en la producción de conocimiento. El diálogo con colegas, las búsquedas de financiamiento, las clases, las evaluaciones, las participaciones en el debate público, las actividades de transferencia o la vinculación tecnológica constituyen nuestras condiciones y posibilidades de producir nuevas ideas: acompañar es caminar junto a otros; pero somos, en definitiva, caminantes siguiendo nuestro propio sendero.

Si acompañamos a un maestro/a agricultor/a y aprendemos por fin "los movimientos exactos que hacen que un envuelto de maíz tome la forma y la consistencia precisa”, seguiremos siendo antropólogos/as que ahora pueden analizar con mayor precisión las técnicas agrícolas. El trabajo de campo nos transforma, así como transformamos a nuestros interlocutores en el encuentro, pero el aporte de nuestro trabajo será teórico: entenderemos mejor eso que queríamos saber y que seguramente está conectado con problemas sociales más o menos reconocidos (Rockwell 2009).

Por eso, ciertamente, nuestros aprendizajes serán también valiosos para los interlocutores que se han vinculado con nosotros con expectativas recíprocas: no se han dejado acompañar por sus pares sino por un/a antropólogo/a con una práctica profesional —ojalá éticamente orientada a la atención solidaria a las necesidades de los otros- que puede contribuir a una sociedad con mayor igualdad.

\section{Referencias}

Batallán, Graciela y José Fernando García. 1992. “Antropología y participación. Contribución al debate metodológico”. Publicar: en Antropología y Ciencias Sociales 1 (1): 79-89. http://cidac.filo.uba.ar/sites/cidac.filo.uba.ar/files/revistas/adjuntos/UNIDAD\%2013\%20 -\%20Antropolog\%C3\%ADa\%20y\%20Participaci\%C3\%B3n.pdf 
Bourdieu, Pierre y Loïc Wacquant.1995. Respuestas por una antropología reflexiva. Ciudad de México: Grijalbo.

Coy, Michael. 1989. Apprenticeship. From theory to method and back again. Albany: Suny Press.

Díaz de Rada, Ángel. 2010. "Bagatelas de la moralidad ordinaria. Los anclajes morales de una experiencia etnográfica”. En Dilemas éticos en antropología. Las entretelas del trabajo de campo etnográfico, editado por Margarita del Olmo Pintado, 57-76. Madrid: Editorial Trotta.

Ingold, Tim. 2002. The perception of environment. Londres: Routledge.

Jimeno, Myriam. 2005. "La vocación crítica de la antropología en Latinoamérica”. Antípoda 1: 43-65. https://doi.org/10.7440/antipoda1.2005.03

Lave, Jean y Étienne Wenger. 1991. Situated learning: legitimate peripheral participation. Cambridge: Cambridge University Press.

Rockwell, Elsie. 2009. La experiencia etnográfica. Historia y cultura en los procesos educativos. Buenos Aires: Paidós. 


\section{El oficio del etnógrafo}

Joanne Rappaport

Georgetown University, Estados Unidos

M

is reflexiones iniciales al leer el artículo de Guzmán y Suárez giraron en torno a lo que para mí constituye la práctica de la etnografía: estar, acompañar y participar en los quehaceres diarios y los eventos especiales. Las entrevistas formales, encuestas, talleres, etc. forman parte de la etnografía, pero la base de la práctica de etnógrafas y etnógrafos es pasar tiempo juntos -la expresión en inglés para esto sería deep hanging out-. Esto es precisamente lo que proponen Guzmán y Suárez. Me imagino que es una respuesta a las cambiantes prácticas etnográficas de las últimas décadas, mediante las cuales los investigadores llegan, recolectan su material y ni siquiera duermen en la comunidad. Aunque posiblemente se trate de una reacción a la violencia, muchos campesinos lo entienden, según me han contado ellos mismos, como un rechazo a su manera de vivir y a su hospitalidad.

En mi propio trabajo sobre el movimiento indígena en el Cauca aprendí que es importante pasar tiempo en las comunidades para poder entender cómo la gente de a pie - los que nutren las movilizaciones-entiende la política de las organizaciones, porque el movimiento indígena no se dirige únicamente desde la cúpula sino, simultáneamente, desde las mismas comunidades. Claro que uno puede entrevistar a los comuneros, pero en las entrevistas grabadas las cuestiones políticas, educativas, etc. se articulan formulaicamente, sin reflejar las experiencias y los pensamientos de la gente; para eso se necesita un entendimiento "a ras del suelo".

La práctica de deep hanging out funciona en combinación con una negativa a regirse por el proyecto original, como enfatizan Guzmán y Suárez al argumentar que la investigación debe surgir de la misma experiencia en el campo. No obstante, a diferencia de los autores, creo que el proceso de escribir un proyecto de investigación vale la pena en la medida en que ayude al investigador a generar los múltiples caminos posibles para su pesquisa. Sin embargo, este tiene que ser un ejercicio de imaginación, no una ruta definitiva a seguir. En el campo, uno tiene que seguir su intuición: escuchar a la gente, observar qué consideran

rappapoj@georgetown.edu / https://orcid.org/0000-0002-7602-7117 
importante, abrirse a las perspectivas que proponen. Por ejemplo, en mi trabajo sobre los investigadores del Consejo Regional Indígena del Cauca, fue a lo largo de varias temporadas de investigación que me di cuenta de que era importante incluir a los colaboradores no indígenas como sujetos de investigación, a instancias de los varios interlocutores que conocí en el camino. Estos colaboradores no figuraban en mi proyecto inicial.

Una reflexión posterior sobre el artículo me llevó a pensar en cómo se puede compartir esa cotidianidad en los contextos supralocales que muchos etnógrafos suelen estudiar hoy en día: movimientos sociales, instituciones gubernamentales e internacionales, regiones, etc. La propuesta de Guzmán y Suárez funciona para los entornos rurales y, tal vez, para una antropología urbana localizada. Sin embargo, en muchos casos es imposible compartir las labores cotidianas porque son demasiado especializadas o porque hay restricciones que lo impiden: por ejemplo, investigaciones sobre la cultura de los laboratorios, los juzgados o con militares. Obviamente, en estos casos la observación y las entrevistas dirigidas cobran más importancia, pero, de todas formas, resulta necesario pensar qué significa, en estos contextos, deep hanging out, es decir, cómo hacer posible captar su cotidianidad.

Guzmán y Suárez traen a colación uno de los problemas que yo considero centrales en el ejercicio etnográfico: ¿cómo hacer que no sea un proceso extractivo? Para estos autores, lo que hace que la etnografía sea extractiva es el hecho de restringir la investigación a los temas y metodologías prestablecidos en el proyecto inicial. Yo agregaría que, aunque es cierto que las metodologías colaborativas pueden mitigar el carácter extractivista de la etnografía, muchas veces también tienden a limitar la investigación a las preguntas preestablecidas y a ciertas técnicas previstas por los investigadores. No obstante, creo que tenemos que ir más allá y reflexionar sobre el porqué de la investigación etnográfica: ¿qué quieren hacer los etnógrafos con los aprendizajes que adquieren en el campo?, ¿para qué hacemos etnografía? Es importante pensar en cómo se comunica lo que se ha aprendido, a quiénes, por qué medios y en qué lenguaje. ¿Cuál debería ser la relación entre el acompañamiento en el campo y los argumentos finales?, ¿hasta qué punto y con qué métodos se retiene la voz de la comunidad?, ¿a quiénes está dirigido y en qué formatos? Son preguntas importantes y contestarlas no es tan fácil como uno supondría, pues las necesidades de la comunidad y las de los investigadores no siempre están alineadas y no siempre tenemos el entrenamiento adecuado para comunicar los resultados en formatos asequibles. Finalmente, ¿quién tiene el derecho de hacer etnografía? Esta cuestión se está debatiendo en muchas comunidades indígenas hoy en día y nos sugiere que nuestra 
práctica de visitar a la gente y extraer información de ella no es un proyecto viable o sostenible a largo plazo. La reflexión de Guzmán y Suárez nos urge y nos insta a pensar en esas importantes preguntas. 


\section{Compañias buenas para vivir: respuesta a los comentarios}

Laura Guzmán Peñuela

Luis Alberto Suárez Guava

a antropología no es una cosa finalizada ni un modo de hacer igual a sí mismo. Su vitalidad es notoria en las múltiples discusiones que se suscitan cada tanto y de las cuales sale cambiada y, acaso, para algunos gustos, irreconocible. Por suerte se siguen dando las discusiones y a veces tenemos ocasión de advertir que están ocurriendo. Esta discusión que ha permitido la RCA es uno de esos momentos afortunados.

Para comenzar nuestro comentario, dos asuntos requieren precisión: 1) no nos referimos a la etnografía o al trabajo etnográfico ni pretendemos depurarlos o reformular una receta correcta; 2) sí consideramos que la antropología supone una tarea teórica, conceptual y amarrada a la vida. Creemos con Ingold (2017) que la confusión entre antropología y etnografía termina ocultando el potencial transformador de la primera. Así que nuestro llamado no es a esforzarnos por tener más autoridad para esgrimir los argumentos usuales, repetidos, sin alma y previsibles, tal como ha notado en su comentario Diego Cagüeñas. Al acompañar la vida que trabaja nos pondremos en mejores condiciones para asumir la tarea inacabada de plantear discusiones teóricas. Estos diálogos serán el producto del modo de hacer: no el mero pensamiento esforzándose por pensar distinto, sino un aprendizaje a ras del suelo que nos enseña otros conceptos o nos obliga a buscarlos para dar cuenta de lo que nos enseñaron.

Esta propuesta es acerca de cómo podríamos hacer antropología, reconociendo que se ha hecho de múltiples formas y que esas formas coexisten, aunque tomamos distancia de algunas. Nuestro planteamiento responde a dos aspiraciones: 1) aprender de las personas con quienes trabajamos y ser los aprendices de lo que nos pueden enseñar; y 2) hacer lo necesario, pero no solo de pensamiento y palabra, para alterar el orden de las relaciones desiguales entre investigadores e investigados. Compartir las ocupaciones de la gente que nos recibe en campo es la forma que hasta ahora hemos encontrado para alcanzar esos propósitos. No buscamos recaudar información, sino lograr aprendizajes acerca de cómo seguir llevando la vida junto con otros seres en un mundo igualmente vivo. Habría que 
reconocer que hay modos de vida y trabajo a los cuales se les oculta la vitalidad del mundo. Incluso, que seguir algunos de esos trabajos atentaría contra la vitalidad de la antropología. Es cierto, entonces, que esta propuesta no sirve para todas las antropologías ni nos gustaría que así fuera.

No pretendemos ni proponemos que la antropología sea una disciplina dedicada solamente a la transcripción (aunque en ocasiones esa sola tarea pueda ser iluminadora). Pero debemos tener cuidado con el "algo más” que decimos cuando las personas que nos educan en campo nos plantean argumentos y modos de hacer y de vivir que transgreden nuestro sentido de la realidad. Inevitablemente, quienes a esto nos hemos dedicado tendremos que escribir textos y esos textos dirán "algo más”. Escribir también es un trabajo que nos ayuda a comprender lo que sin el trabajo de escribir no lograríamos. Pero en esos textos nuestros maestros y maestras no serán el objeto sobre el cual sobrevuela el saber antropológico para demostrar algún argumento. En cambio, serán autoras y autores de conocimiento y ocuparán en nuestros textos el mismo lugar que las referencias bibliográficas, que nuestros compañeros de universidad y que nuestras profesoras y profesores. Esos textos que tendremos que esforzarnos por escribir eventualmente nos ayudarán a encontrar modos más justos de vivir juntos.

Por otro lado, estamos demasiado acostumbrados a creer que lo propio y lo fundamental de la antropología es lo que queda en los textos. Creemos que, al compartir la vida en el trabajo material, como antropólogas y antropólogos podremos notar que queda "algo más": los productos mismos del trabajo — que no son poca cosa y en muchos casos serán aquello por lo cual nos recuerden-, pero, sobre todo, quedarán las amistades de largo aliento. Habrá enseñanzas que no aparecerán en texto porque o no alcanzamos a elaborarlas o no pueden ser escritas. Y, sin embargo, son un producto de la antropología que nos acompaña durante nuestra vida luego del campo. Trabajar tiene un valor formativo que dura más tiempo que el de la escritura de los informes de investigación. También permite ampliar nuestras comprensiones acerca de todo y, con ello, las posibilidades de la antropología.

Creemos en la potencia del trabajo de campo porque nos permite aprender desde dentro (ver Ingold 2015). No pretendemos acompañar el trabajo para de este modo reconstruir lo que hace la gente ni para mejorar nuestras descripciones. Estar inmersos en el trabajo reconociendo nuestra ignorancia nos permitirá encontrar propósitos de investigación junto a la gente con la que trabajamos, en lugar de imponerlos o acomodarlos a las expectativas de los financiadores o de lo que sea tendencia; en esto nos apartamos del argumento de Ana Padawer. Llegar al terreno con propósitos de investigación predeterminados e inmutables es como llegar con las manos extendidas hacia un regalo que queremos (que suele ser información) y por el cual no siempre es claro qué devolveremos. Lo peor de 
esa relación de dominación no es que los investigadores no devuelvan el don. Lo peor es cuando quienes fueron objetos de esas investigaciones descubren que estaban en medio de una falsa amistad o de un escrutinio encubierto. Es como si por habernos formado en las universidades nos sintiéramos con derecho a obtener esa información que queremos y creemos debe ser nuestra o de la disciplina.

Al contrario, si lo que recibimos cuando hacemos trabajo de campo es formación y no datos, tendremos que aceptar una relación que no puede tener cierre: la deuda nos obligará primero a volver y luego nos permitirá reconsiderar qué tan otros somos. Para nosotros, el camino de la antropología no tiene mucho sentido si no se hace con nuestras maestras y maestros de trabajo de campo. Es con esas personas y por esas personas que tiene sentido la búsqueda de modos de vivir en un mundo más justo. Apartarnos de ellas en el supuesto de que los espacios académicos tienen su propio camino es haber perdido el horizonte.

Tiene mucha razón Joanne Rappaport cuando afirma que la "práctica de visitar a la gente y extraer información de ella no es un proyecto viable o sostenible a largo plazo”. ¿Será que el bienestar de la antropología o el avance del conocimiento son razones suficientes para seguir viviendo de esos extractivismos de datos? El problema radica en que eso es lo que estamos enseñando en las universidades, lo que creemos que debemos hacer cuando pensamos en la investigación y lo primero que se nos ocurre cuando decimos “antropología”. De modo que, aunque no es éticamente sostenible, sí se ha demostrado simbólicamente muy rentable.

Aceptemos la tarea de ser aprendices de quienes llevan la vida a ras del suelo. Tal vez logremos atisbar algún resquicio de la igualdad que a veces solo aparece en el plano de los buenos propósitos. Tal vez consigamos ser reconocidos no ya solo como conciudadanos sino también como compañías buenas para vivir.

\section{Referencias}

Ingold, Tim. 2015. "Conociendo desde dentro: reconfigurando las relaciones entre la antropología y la etnografía”. Etnografías Contemporáneas 2 (2): 218-230. https://revistasacademicas.unsam.edu.ar/index.php/etnocontemp/article/view/410

—. 2017. “¡Suficiente con la etnografía!”. Revista Colombiana de Antropología 53 (2): 143-159. https://doi.org/10.22380/2539472X.120 